\title{
Alterações do perfil ocupacional da população em situação de sem-abrigo na cidade de Leiria
}

\section{Changes in the occupational profile of the homeless population at the city of Leiria}

\author{
Alexandra Guerra Neves ${ }^{1}$, Ana Catarina da Fonseca Peters ${ }^{2}$, \\ Maria Inês Gil Andrade ${ }^{3}$, Sara Maria Santos Vaz da Silva ${ }^{4}$, \\ Jaime Emanuel Moreira Ribeiro ${ }^{5}$, Maria Dulce das Neves Gomes ${ }^{6}$
}

http://dx.doi.org/10.11606/issn.2238-6149.v30i3p150-159

\begin{abstract}
Neves AG, Peters ACF, Andrade MIG, Silva MSN, Ribeiro JEM, Gomes MDN. Alterações do perfil ocupacional da população em situação de sem-abrigo na cidade de Leiria. Rev Ter Ocup Univ São Paulo. 2020 set.-dez.;30(3):150-9.

RESUMO: Introdução: O conceito de pessoa em situação de rua, também designado por pessoa em situação de sem-abrigo, representa qualquer indivíduo que esteja destituído de uma habitação e privado dos bens essenciais. Isto acarreta problemas a nível físico, psicossocial e emocional, podendo alterar os hábitos, rotinas e papéis destes indivíduos. Objetivo: Conhecer e descrever as alterações do perfil de saúde, em concreto do perfil ocupacional, da população em situação de sem-abrigo na cidade de Leiria, antes e na atual situação. Métodos: Estudo de caso descritivo, de abordagem qualitativa, com recurso à recolha de dados por entrevista semiestruturada. A análise de conteúdo foi efetuada por meio do software webQDA de apoio à análise de dados qualitativos num ambiente colaborativo e distribuído. Amostra: Quatro indivíduos na situação de sem-abrigo residentes na cidade de Leiria, agregados ao Centro de Acolhimento de Leiria. Resultados/Conclusão: São identificadas alterações de Papéis e Contextos e Ambientes nos indivíduos em situação de sem-abrigo, onde se destacam a perda de papéis sociais e de relações familiares, as condições habitacionais precárias e o recurso continuado a apoios sociais. Sobrepõe-se a destruturação das rotinas o que conduz ao desequilíbrio ocupacional.
\end{abstract}

PALAVRAS-CHAVE: Atividades humanas; Perfil de saúde; Pessoas em situação de rua; Terapia ocupacional.
Neves AG, Peters ACF, Andrade MIG, Silva MSN, Ribeiro JEM, Gomes MDN. Changes in the occupational profile of the homeless population at the city of Leiria. Rev Ter Ocup Univ São Paulo. 2020 Sept.-Dec.;30(3):150-9.

ABSTRACT: Introduction: The homeless person concept represents any individual who is deprived of a habitation and essential needs. These facts increase physical, psychosocial and emotional problems and may modify the habits, the routines and the roles of these individuals. Objective: To know and describe the changes in the occupational profile of the homeless population in the city of Leiria, before and in the current situation. Methods: Descriptive case study, with a qualitative approach, using data collection by semi-structured interview. Content analysis was performed using webQDA software to support qualitative data analysis in a collaborative and distributed environment. Sample: Four homeless people, residents in the city of Leiria, added to the Centro de Acolhimento de Leiria. Results/Conclusion: Changes in Roles and Contexts/Environments are identified in homeless individuals, in which the loss of social roles and family relationships, poor housing conditions and continued use of social support are highlighted. It overlaps the routinization of routines, which leads to occupational imbalance.

KEYWORDS: Human activities; Health profile; Homeless persons; Occupational therapy.

Projeto Final do Curso de Licenciatura em Terapia Ocupacional realizado na Escola Superior de Saúde do Politécnico de Leiria no âmbito da unidade curricular Trabalho Final de Curso. Projeto apresentado pelos autores no evento "Segunda Edição das Jornadas Internas de Terapia Ocupacional", realizado na Escola Superior de Saúde do Politécnico de Leiria, no dia 7 de junho de 2019.

1. Aluna do $4^{\circ}$ ano do Curso de Licenciatura em Terapia Ocupacional da Escola Superior de Saúde do Politécnico de Leiria. ORCID: https://orcid.org/0000-0001-5079-1128. E-mail: alexandra_neves_12@hotmail.com.

2. Aluna do $4^{\circ}$ ano do Curso de Licenciatura em Terapia Ocupacional da Escola Superior de Saúde do Politécnico de Leiria. ORCID: https://orcid.org/0000-0003-1211-3072. : anacatarinapeters.to@gmail.com.

3. Aluna do $4^{\circ}$ ano do Curso de Licenciatura em Terapia Ocupacional da Escola Superior de Saúde do Politécnico de Leiria. ORCID: https://orcid.org/0000-0003-0177-174X. E-mail: inesgilandrade@icloud.com.

4. Aluna do $4^{\circ}$ ano do Curso de Licenciatura em Terapia Ocupacional da Escola Superior de Saúde do Politécnico de Leiria. ORCID: https://orcid.org/0000-0001-6235-8305. E-mail: saravazsilva6@gmail.com.

5. Professor Adjuntos da Escola Superior de Saúde do Politécnico de Leiria. ORCID: https://orcid.org/0000-0002-1548-5579. E-mail: jaime.ribeiro@ipleiria.pt.

6. Professora Adjuntos da Escola Superior de Saúde do Politécnico de Leiria. ORCID: https://orcid.org/0000-0003-4526-3990. E-mail: dulce.gomes@ipleiria.pt.

Endereço para correspondência: Maria Dulce das Neves Gomes. Campus 2- Morro do Lena - Alto do Vieiro. Apartado 4163 | 2411-901 Leiria, Portugal. 


\section{INTRODUÇÃO}

$\mathrm{O}$ conceito de pessoas em situação de sem-abrigo, designada nos Descritores em Ciências da Saúde ${ }^{1}$ como pessoas em situação de rua, compreende todos os indivíduos que se encontram "sem teto" ou "sem casa", "independentemente da sua nacionalidade, origem racial ou étnica, religião, idade, sexo, orientação sexual, situação socioeconómica e situação de saúde física e mental", segundo a Estratégia Nacional para a Integração das Pessoas em Situação de Sem-Abrigo 2017-2023 (ENIPSSA 2017-2023) (p. 9)².

A pessoa em situação "sem teto", poderá viver num espaço público, espaços de utilização pública como jardins, pontes, entre outros; num abrigo de emergência, que se entende por qualquer local que aloje de forma imediata e gratuita e por curta duração; num local precário, que devido às suas condições de abandono possibilita uma utilização pública, como edifícios e carros abandonados. A pessoa que se encontra na situação "sem casa", mais especificamente em alojamento temporário, poderá estar inserida em locais de acolhimento, instalações temporárias, que promovam a inserção social do indivíduo².

O conceito proposto pela ENIPSSA 2017-2023, elaborado tendo por base as categorias operacionais da European Typology of Homelessness and housing exclusion (ETHOS) ideada pela Federação Europeia das Associações que Trabalham com os Sem-Abrigo (FEANTSA), visa possibilitar a utilização dos mesmos critérios (definidos acima para as condições de "sem teto" e "sem casa") para o levantamento e caracterização, planeamento, intervenção e resposta mais direcionada à população portuguesa em situação de sem-abrigo ${ }^{2,3}$.

A ETHOS compreende o fenómeno das pessoas em situação de sem-abrigo e as suas realidades por toda a Europa, descrevendo-as segundo quatro grupos, nos domínios físico, legal e social, em: sem teto (Roofless), sem alojamento (Houseless), inseguro (Insecure) e inadequado (Inadequate). O primeiro grupo corresponde às pessoas sem posse de habitação legal que pernoitam na rua; sem alojamento refere-se a pessoas que usufruem de habitação, contudo não detêm a posse exclusiva desta; o grupo intitulado inseguro, diz respeito a pessoas com habitação e espaço de desenvolvimento das relações sociais, porém é inseguro de habitar; e por último inadequado, inclui pessoas com posse legal de habitação, todavia vivem em moradias impróprias ou em sobrelotação ${ }^{4}$.

A situação de sem-abrigo resulta do percurso de desintegração, ausência de perspetivas, degradação das relações pessoais e afastamento laboral que poderão culminar numa crise identitária ${ }^{5}$. Este percurso poderá ter na sua base múltiplas perdas sucessivas, consequentes de problemas familiares, carência económica, desemprego, perda de alojamento e problemas de saúde, fatores que conduzem à privação dos bens essenciais ${ }^{6,7}$. Na população em situação de sem-abrigo é verificado o agravamento de problemas de saúde mental e física dado o stress ambiental e psicológico a que está sujeita. A dependência de drogas e álcool constitui uma problemática nesta população e os défices relacionados com a higiene e nutrição adequada, poderão repercutir no seu estado de saúde ${ }^{8}$.

A pessoa constrói e desenvolve a sua identidade a partir da sua interação em ocupações e, portanto, é considerada como um "ser ocupacional". Para explicar esta preposição, define-se o termo ocupação como o conjunto de atividades com propósito, também entendido como atividades humanas, em que o indivíduo se envolve e que concedem significado à sua vida, ocorrendo e sofrendo a influência do contexto temporal, social e cultural, dos fatores pessoais e da dimensão espiritual ${ }^{1,9}$. A ocupação é organizada em áreas, distinguindo-se Atividades da Vida Diária (AVDs), Atividades da Vida Diária Instrumentais (AVDIs), Educação, Trabalho, Lazer, e Descanso e Sono. As AVDs incluem todas as atividades que garantam a sobrevivência e o bem-estar - tomar banho, higiene, vestir, alimentar, entre outras; as AVDIs dão suporte à vida diária em casa e na comunidade e abrangem parâmetros como a gestão financeira, a gestão e manutenção da saúde (GMS) e a preparação de refeições e limpeza; a Educação referese às atividades essenciais à aprendizagem (participação académica, não académica, extracurricular, pré-vocacional e vocacional); o Trabalho diz respeito ao envolvimento em estratégias de geração de renda, o que inclui o emprego, os trabalhados informais, as cooperativas de trabalho, entre outros; o Lazer inclui todas as atividades realizadas durante o tempo livre, que confiram sensação de prazer e bem-estar à pessoa que as pratica; e o Descanso e Sono, enquadrado na GMS, considera as atividades que diminuem a atividade física e mental, permitindo o relaxamento e o período de permanência no dormir ${ }^{10}$.

O envolvimento em ocupações é abordado segundo os padrões de desempenho observados nos Hábitos, nas Rotinas e nos Papéis. Por Hábitos entendem-se todos os comportamentos/mecanismos integrados nos padrões de vida quotidianos, que permitem que a pessoa haja automaticamente; as Rotinas são o conjunto de comportamentos frequentes e estruturantes do quotidiano, que obedecem a uma sequência estabelecida de ocupações e atividades; e por último, os Papéis incluem os comportamentos contextualizados e definidos 
que se moldam em relação ao ambiente e ao contexto cultural, no qual se inserem. O desempenho ocupacional ocorre num ambiente físico e social, estando intimamente dependente destes e dos contextos em que o indivíduo se insere, influenciando a qualidade e a satisfação do mesmo . $\mathrm{O}$ ambiente assume repercussões sobre a ocupação podendo suportar, oferecer oportunidades, requerer determinadas exigências ou apresentar obstáculos ao desempenho da mesma $^{11}$. Sabendo que os ambientes e contextos físicos e sociais das pessoas em situação de sem-abrigo se encontram comprometidos, com condições precárias e laços sociais estreitos, e que os padrões de desempenho estabelecem uma inter-relação dinâmica com as ocupações e os contextos e ambientes, estes padrões poderão encontrar-se alterados ${ }^{2,7,12}$.

A Terapia Ocupacional é a profissão de referência no que concerne à inclusão social, sendo um meio para a promoção da saúde e do bem-estar. Dentro do perfil de saúde, enquadra-se o perfil ocupacional, que é resultado da história ocupacional, padrões de desempenho, interesses e necessidades de um indivíduo, como forma de determinar as ocupações em risco, os facilitadores e as barreiras ao envolvimento ocupacional e as experiências passadas que contribuam para a compreensão dos problemas atuais ${ }^{1,12}$.

A ENIPSSA (p. 7) ${ }^{13}$ traçou o perfil geral para a população portuguesa em situação de sem-abrigo em 2009, para uma amostra de 2133 , em que $82 \%$ são de nacionalidade portuguesa, $84 \%$ são do sexo masculino, $60 \%$ têm idades compreendidas entre os 30 e 49 anos e o grau de habilitações mais frequente é o $1^{\circ}$ ciclo (31\%). As necessidades de apoio centram-se em questões de saúde e défice ocupacional ${ }^{13}$. Em 2018 o número de pessoas em situação de sem-abrigo, em Portugal Continental, era de 3396, sendo que na região de Leiria se encontravam nesta situação 55 pessoas ${ }^{14}$.

Tendo como objetivo identificar as principais alterações de Hábitos, Rotinas, Papéis e Contextos e Ambientes de pessoas em situação de sem-abrigo da cidade de Leiria, conduzimos este estudo partindo da questão: Quais as alterações do perfil ocupacional da população que passou à situação de sem-abrigo na cidade de Leiria?

\section{PROCEDIMENTOS METODOLÓGICOS}

Este estudo, descritivo de abordagem qualitativa, é caracterizado por abordar um fenómeno contemporâneo em contexto de vida real, tendo-se adotado a estratégia de estudo de caso $^{15}$.

Foi utilizada a entrevista semiestruturada como método de recolha de dados, junto de indivíduos que se encontram na situação de sem-abrigo e que frequentam o Centro de Acolhimento de Leiria (CAL). Foram selecionados quatro participantes que cumpriam os critérios de inclusão: viver em Leiria; ter idade igual ou superior a 18 anos; e aceitar participar na entrevista. Foram excluídos possíveis participantes identificados pela Coordenadora do CAL, com alterações das funções superiores evidentes que comprometessem a entrevista.

As entrevistas foram realizadas no CAL, local familiar e confortável para os participantes. Cada entrevista foi conduzida por dois investigadores juniores e um investigador sénior, com a duração média, tolerada pelos participantes, de 20 minutos e com o foco nas áreas em estudo: Hábitos, Rotinas, Papéis e Contextos e Ambientes. As entrevistas foram gravadas e o conteúdo transcrito para posterior análise.

Na recolha, tratamento e divulgação dos dados, foram preservados os princípios formais e éticos previstos pela declaração de Helsínquia e validados pela Comissão de Ética do Politécnico de Leiria.

Para a análise de conteúdo foi utilizado o software webQDA, facilitando o processo de tratamento de dados na sua organização, divisão em unidades manipuláveis, sintetização da informação e identificação dos padrões existentes e das informações mais relevantes ${ }^{16}$ multimedia. $\mathrm{O}$ processo iniciou-se com a importação da transcrição integral de cada entrevista, tendo sido atribuído um código a cada entrevistado- E1, E2, E3 e E4. O processo de categorização, entenda-se como sendo o agrupamento de unidades de análise com significado semelhante, pressupõe-se encontrar sentido para os dados, de acordo com o problema de investigaçãa ${ }^{17,18}$. Após uma leitura "flutuante" de Pardal e Lopes ${ }^{17}$, Sampieri et al. ${ }^{18}$ e Bardin ${ }^{19}$ foram então definidas duas categorias emergentes: "Antes da Situação de Sem-abrigo" " "Na Situação de Sem-abrigo". A construção e descrição das subcategorias fundamentam-se no Enquadramento da Prática da Terapia Ocupacional: Domínio \& Processo (2 ${ }^{a}$ Edição). Dentro destas, distinguiram-se quatro subcategorias - Hábitos, Rotinas, Papéis e Contextos e Ambientes -, sendo que na categoria "Na Situação de Sem-abrigo", se acrescentaram dois novos itens, "Objetivos de Vida", dada a importância que estes assumem na volição, influenciando o envolvimento dos indivíduos em atividades significativas, promotoras de mudanças nestes e no seu percurso vivencial, e "Frequenta o Centro de Acolhimento de Leiria", inserido na subcategoria "Rotinas"10,11.

Na Figura 1 é ilustrada a árvore de categorias, para a anterior situação de sem-abrigo e na situação de sem-abrigo. As caixas a tracejado correspondem a duas subcategorias exclusivas desta última categoria. Depois da codificação das entrevistas, quantificaram-se as ocorrências em cada categoria. 


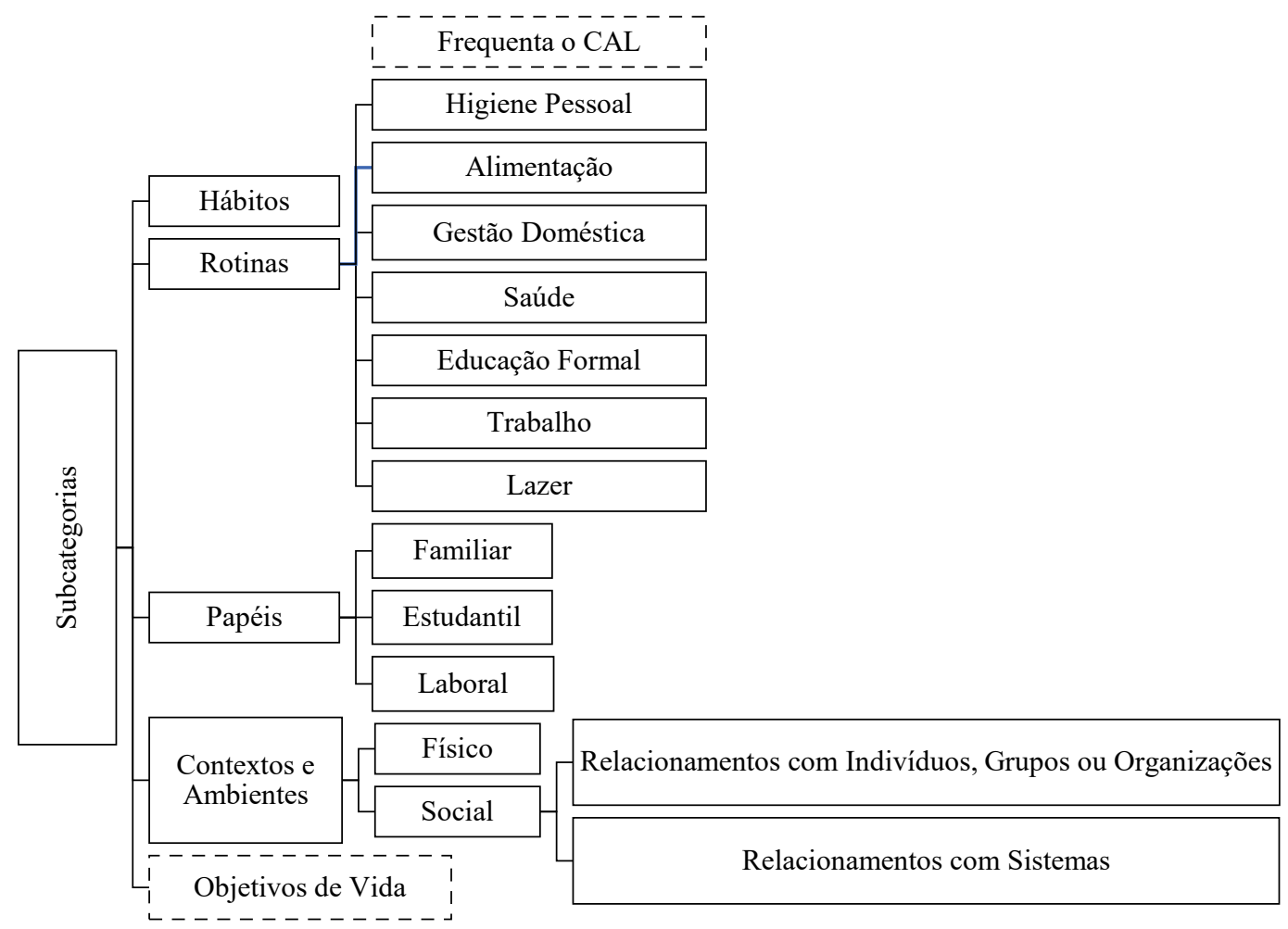

Figura 1- Árvore de subcategorias na anterior e na atual situação de sem-abrigo.

\section{RESULTADOS E DISCUSSÃO}

O presente estudo possui quatro participantes de nacionalidade portuguesa, residentes em Leiria, cujas características se encontram descritas na seguinte tabela (Tabela 1). Dada a amostra existente, os investigadores seguiram o conceito de pessoa em situação de sem-abrigo segundo a FEANTSA ${ }^{4}$, para caracterizar a situação de cada participante.

Os resultados obtidos encontram-se esquematizados nas seguintes Figuras (2 e 3), expondo o número de referências encontradas em cada categoria e subcategoria, por entrevistado. O R1, exposto nas figuras, corresponde aos Relacionamentos com Indivíduos, Grupos ou Organizações e R2, Relacionamentos com Sistemas.

Tabela 1 - Caracterização dos Participantes

\begin{tabular}{lllll}
\hline Participante & E1 & E2 & E3 & E4 \\
\hline Sexo & Masculino & Feminino & Feminino & Masculino \\
Idade & 24 & 64 & 38 & 31 \\
Problemas de Saúde & $\mathrm{X}$ & Artrite reumatoide; & $\begin{array}{l}\text { Neuropatia periférica } \\
\text { sintomática; }\end{array}$ & $\begin{array}{l}\text { Histórico de } \\
\text { internamento } \\
\text { compulsivo. }\end{array}$ \\
& & Histórico de acidente & Esgotamento nervoso. & $9^{\circ}$ ano \\
Escolaridade & $9^{\mathbf{o}}$ ano & vepressão. & & Desempregado \\
Situação Profissional & Desempregado & $12^{\mathbf{0}}$ ano & $7^{\mathbf{0}}$ ano & Sem teto \\
ETHOS (tipologia) & Habitação inadequada & Habitação inadequada & Habitação inadequada & 12 anos \\
Período da situação de & 2 meses & 19 anos & Não definido & \\
sem-abrigo & & & & \\
\hline
\end{tabular}




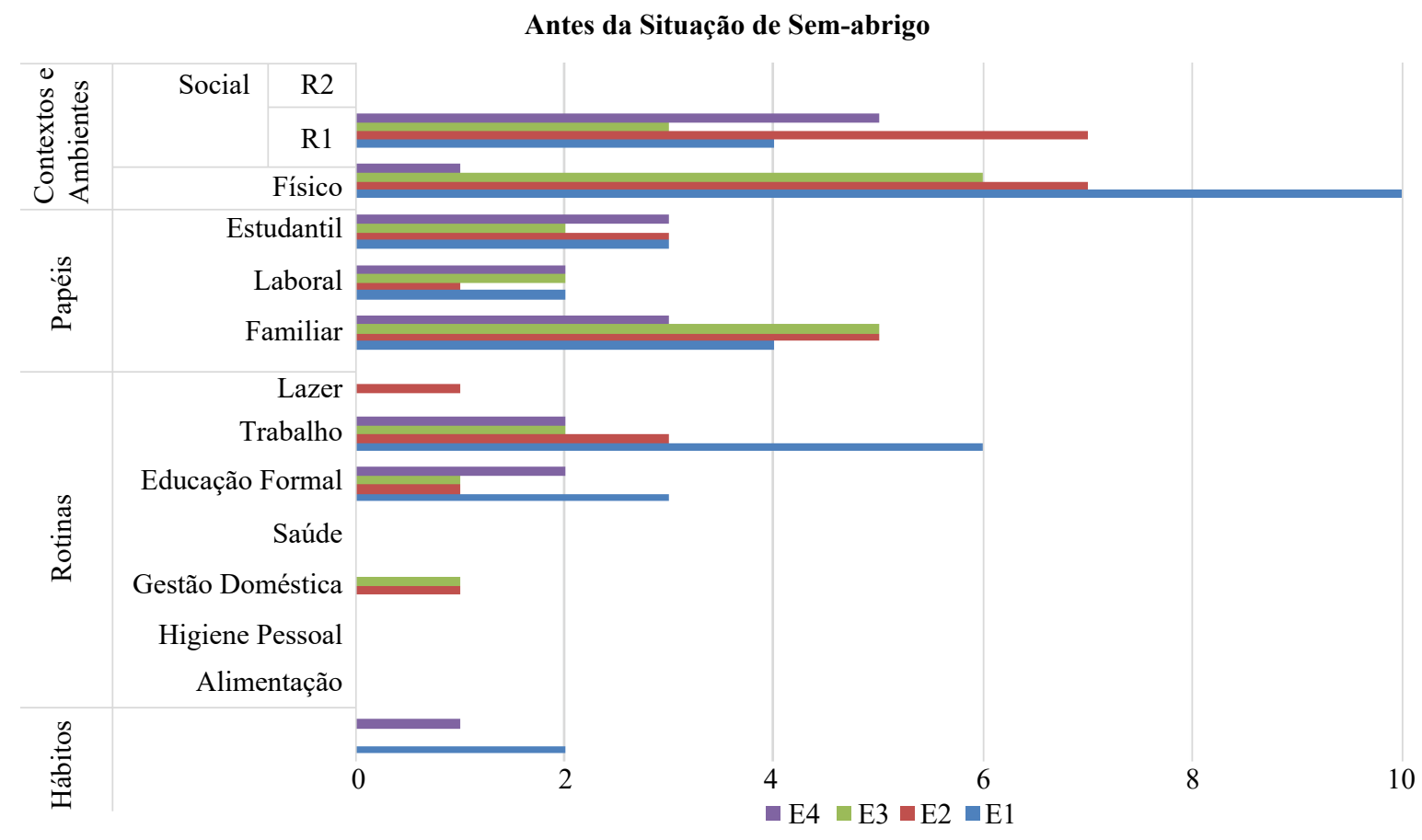

Figura 2 - Conteúdo analisado via webQDA para a categoria "Antes da situação de Sem-abrigo"

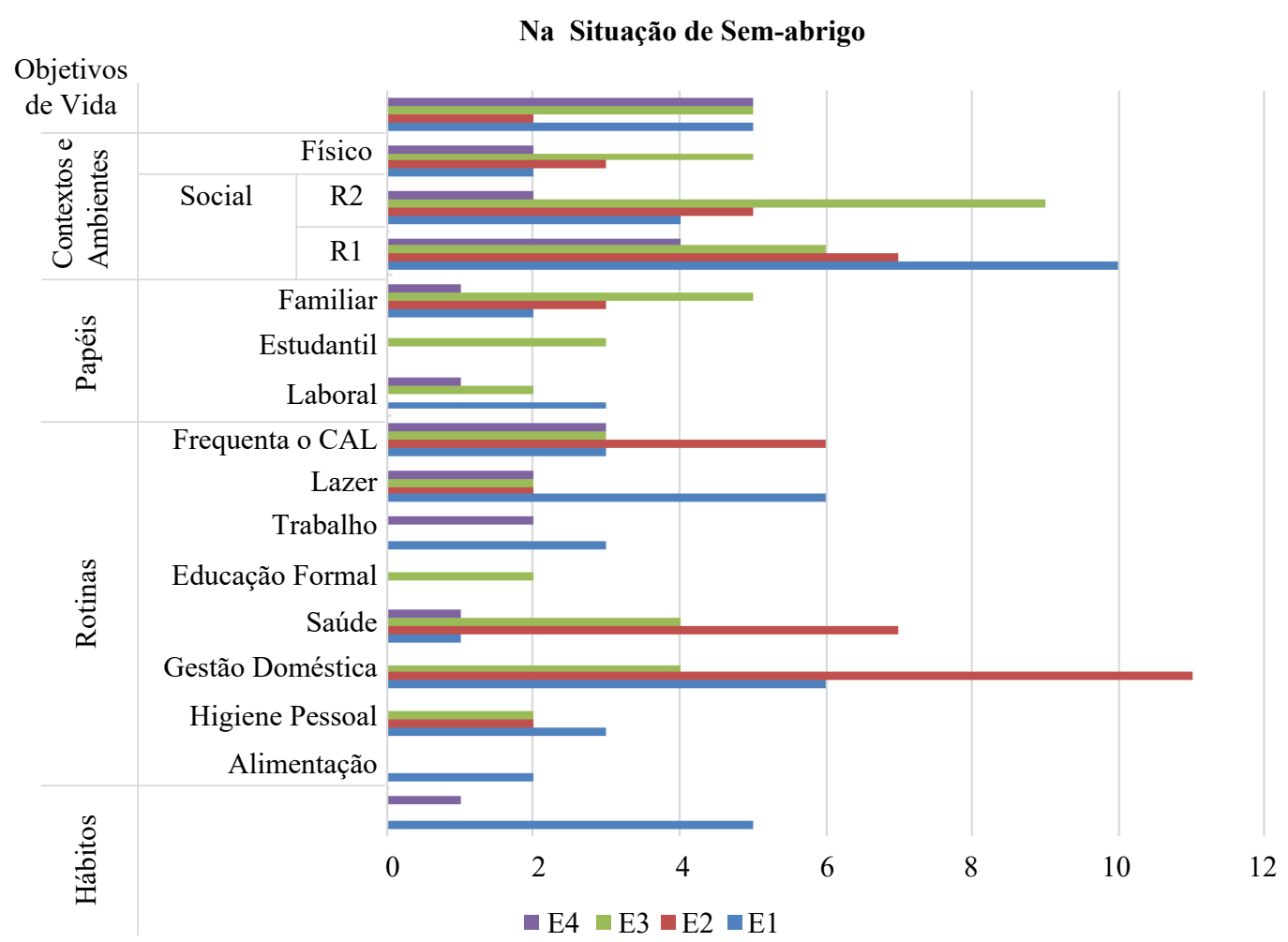

Figura 3 - Conteúdo analisado via webQDA para a categoria "Antes da situação de Sem-abrigo". 
Hábitos

Dentro da subcategoria "Hábitos", analisada antes e na atual situação de sem-abrigo, todos os hábitos aferidos remeteram para o consumo de substâncias que podem ocasionar dependência, tais como o tabaco e drogas (haxixe e marijuana). Este consumo é verificado em metade da população entrevistada, na anterior e atual situação de sem-abrigo. O consumo de substâncias psicoativas é um comportamento frequente na população em situação de sem-abrigo, evidenciado na nossa amostra ${ }^{8}$.

\section{Rotinas}

Nas "Rotinas", antes da situação de sem-abrigo, foram consideradas as seguintes subcategorias de segunda ordem: "Alimentação", "Higiene Pessoal", "Gestão Doméstica"," Saúde", "Educação Formal"," Trabalho" e "Lazer", sendo que na atual situação de sem-abrigo foi ainda acrescentada a subcategoria "Frequenta o Centro de Acolhimento de Leiria".

$\mathrm{Na}$ “Alimentação" e na "Higiene Pessoal" não se verificaram referências que aludam à anterior situação de sem-abrigo, não sendo possível obter termos de comparação. Apesar de na atual situação de sem-abrigo se reunirem referências que apontem para a participação nestas atividades, não foi possível verificar se houve alterações no desempenho ocupacional das mesmas. Contudo, E1 e E3 manifestaram que continuam a participar nestas atividades à semelhança do que faziam antes da situação de sem-abrigo. Apenas E2 referiu dificuldades no envolvimento e execução destas atividades não existindo relação com a situação de sem-abrigo, mas sim com uma patologia associada: "Para me vestir é no mínimo uma hora (...) meia hora é só para amarrar o sapato. Nos banhos (...) tenho um companheiro que nisso ele me ajuda em casa" (E2).

Na subcategoria intitulada "Gestão Doméstica", no que concerne à anterior situação de sem-abrigo, foram mencionadas informações apenas na área da gestão financeira, onde duas fontes, E2 e E3, referiram carência económica: "Me separei do meu marido e fiquei sem condições financeiras para me alimentar" (E2). Já na atual situação de sem-abrigo, foram encontradas respostas que salientam a gestão financeira, no que diz respeito a despesas, dívidas e dificuldade na gestão do dinheiro. As despesas foram mencionadas por três fontes e os principais gastos, prendem-se essencialmente com despesas de habitação e saúde, aluguer de um quarto e tabaco. E3 indicou a existência de dívidas, enquanto que as dificuldades na gestão do dinheiro foram manifestadas por E2 e E3. Ao nível da preparação de refeições e limpeza somente uma fonte referiu dificuldades em fazer a cama, preparar refeições e varrer o quarto, devido ao seu problema de saúde.

Na subcategoria "Saúde" foram considerados os parâmetros gestão da medicação e descanso e sono. Relativamente a esta subcategoria, antes da situação de sem-abrigo, não foram encontradas quaisquer referências. Já na atual situação de sem-abrigo, E2 e E3 expuseram dificuldade na gestão da medicação, sendo o CAL a prestar auxílio nesta atividade: "porque eu antes não tinha controlo, não tomava" (E3). Ambas referiram problemas em dormir, necessitando de medicação, contrariamente a E1, que mencionou não ter problemas nesta área. As primeiras vão ao encontro da informação descrita na literatura, que relata que as pessoas em situação de sem-abrigo não padecem de um sono tranquilo, sendo este afetado pelo fator físico (ambiental) $^{20}$. E4 manifestou não necessitar de medicação.

Relativamente à "Educação Formal", E1 frequentou um curso profissional na área da informática até ao $9^{\circ}$ ano, E2 ingressou no ensino universitário no curso de "Letras Portuguesas e Latina", E3 completou o $7^{\circ}$ ano e E4 participou na educação formal até ao $9^{\circ}$ ano de escolaridade. Atualmente, E3 é a única que mantém na sua rotina o contacto com o sistema educacional, estando integrada numa formação profissional. Dos quatro entrevistados podemos afirmar que mais de metade apresentou níveis de escolaridade baixos.

Na subcategoria "Trabalho", considerando o período antes da situação de sem-abrigo, todos os entrevistados referiram que a atividade laboral fez parte das suas rotinas. Atualmente, o mesmo não se verifica, apenas E1 disse deter alguns trabalhos pontuais, contudo não os enunciou. E1 e E4 afirmaram ter interesse em readquirir um emprego e envolverem-se na procura/pesquisa do mesmo - "Ando a pesquisar sobre trabalho, neste momento oportunidades de trabalho, envio currículos" (E4).

No que concerne ao "Lazer", antes da situação de sem-abrigo, apenas E2 expôs que as atividades manuais e de artesanato, como crochê e tricô, faziam parte das rotinas. As restantes fontes não mencionaram qualquer referência. $\mathrm{Na}$ atual situação de sem-abrigo, entre as principais atividades de lazer estão a atividade física (duas fontes), passear (três fontes), estar com os amigos (uma fonte), ir ao café (duas fontes) e ver televisão (uma fonte). Apesar destas atividades terem sido codificadas na subcategoria lazer, visto referirem-se às atividades praticadas no tempo livre, não é sinónimo que as mesmas sejam significativas para o indivíduo.

Os quatro indivíduos frequentam o CAL ("Frequenta

o Centro de Acolhimento de Leiria") pelo menos duas vezes por dia, para realizarem as suas refeições de almoço 
e jantar. Para além desta atividade, E2 e E3 tomam a sua medicação no Centro e E4 executa a sua higiene pessoal.

A inexistência de um trabalho, a baixa participação na educação formal e o reduzido envolvimento noutras ocupações significativas, conjugados com a sobrevalorização da atividade lazer, dado o elevado tempo livre que lhes resta, gera uma destruturação na rotina na maior parte da amostra, cumprindo apenas horários de frequência ao CAL.

\section{Contextos e Ambientes}

Na subcategoria "Físico", anteriormente à situação de sem-abrigo, encontraram-se no total 24 referências, dez de E1, sete de E2, seis de E3 e uma de E4. Os primeiros três entrevistados têm em comum constantes mudanças de contexto e ambiente físico, numeradas no mínimo cinco alterações de residência. E1 e E4 apresentaram referências relativamente a frequentarem um centro de acolhimento juvenil, E2 viveu com a avó materna e paterna e E3 saiu de casa precocemente por conflitos familiares. No total de todas as informações apuradas, foi congruente a vivência em habitações que reunissem as condições básicas. $\mathrm{O}$ mesmo não se refletiu na atual situação de sem-abrigo, onde três dos indivíduos se encontram a viver em casas partilhadas“(...) sou eu e o F. num quarto, o irmão dele noutro quarto, a T. e o M. noutro quarto, o J. noutro quarto (...)" (E2) - e um a pernoitar em casas abandonadas. Como esperado, ao nível do ambiente físico houve a perda de condições básicas de alojamento, os indivíduos encontram-se numa situação habitacional inadequada ou sem teto (casas abandonadas), devido à carência económica. Estas alterações habitacionais, culminam em dificuldades no acesso a bens essenciais, necessitando de procurar apoio nos sistemas sociais.

Na subcategoria "Social”, anteriormente à situação de sem-abrigo, apenas se encontraram dados referentes aos "Relacionamentos com Indivíduos, Grupos ou Organizações" de onde emergiram unicamente relacionamentos familiares. Neste domínio faziam parte dos relacionamentos de $\mathrm{E} 1$ os tios, os irmãos, os pais adotivos e uma namorada; de E2 o marido, os filhos, as cunhadas, as avós materna e paterna, a mãe e o irmão; de E3 uma filha, os pais e um irmão; e de E4 os pais adotivos e os irmãos. Analisando a mesma subcategoria na atual situação de semabrigo, E1 manteve o relacionamento com os pais adotivos e irmãos; E2 manteve a relação com os filhos, apesar destes se encontrarem geograficamente distantes, com o marido, embora divorciados mantêm uma relação de amizade, e estabeleceu novas relações com um novo companheiro e com netos; E3 relaciona-se atualmente com uma tia materna e com um namorado, não ficando explícito se manteve a relação com o irmão; e E4 afirmou manter relação com os pais adotivos - "Sim, à distância mas sim, um bocado à distância" (E4) -, embora estes se encontrem emigrados. Surgiu ainda o relacionamento com amigos presentes em todos os participantes, apesar de E4 referir: "não são amigos, são conhecidos". Da interpretação do supramencionado podemos confirmar que existiu perda de relacionamentos familiares. Cardoso (p. 27) ${ }^{21}$ que deveriam ser implementadas consoante as diferentes necessidades locais. Após a criação do Núcleo de Planeamento e Intervenção Sem Abrigo (NPISA, evidencia mudanças na estrutura familiar ou afastamento/ ruturas familiares em indivíduos em situação de sem-abrigo, relacionadas com conflitos familiares ou com os progenitores ("família de origem") ou ao divórcio ("família criada"). O ambiente social, tornou-se mais empobrecido na medida em que as relações que mantêm são mais irregulares. Estas relações são caracterizadas por terem uma durabilidade e proximidade mais diminuída, podendo ser inconstantes e passageiras $^{22}$.

Ainda na subcategoria "Social", na atual situação de sem-abrigo, no que pertence aos "Relacionamentos com Sistemas", foram identificadas duas principais relações, no que diz respeito ao apoio social e económico: com o CAL (comum aos quatro entrevistados), que presta apoio ao nível da alimentação, higiene e gestão da medicação; e com a Segurança Social (SS), que assegura o subsídio de desemprego recebido por E1, a pensão por invalidez adquirida por E3 e uma reforma indeterminada referenciada por E2: "Tenho reforma. Quer dizer agora é prestação social". Aquando esta análise não foi possível determinar o estatuto socioeconómico dos entrevistados, devido à imprecisão e noção dos seus direitos sociais e à incapacidade dos investigadores assegurarem a veracidade dos factos revelados. Existe ainda um entrevistado que recebe apoio alimentar das carrinhas de apoio e de outras entidades que auxiliam o acesso a vestuário - "Vou à Caritas ou vou à Cruz Vermelha. Nos dão roupa. Esta roupa é de lá" (E3) -, e outro que recebe apoio da Câmara Municipal de Leiria para a compra da medicação. A subsistência destes indivíduos é, desta forma, assegurada pelas relações que estabelecem com os apoios sociais.

\section{Papéis}

Ao nível "Familiar", esta subcategoria foi analisada para a anterior situação de sem-abrigo, identificando-se quatro papéis desempenhados por E1, cinco por E2, três por E3 e dois por E4. Na atual situação de sem-abrigo encontraram-se dois papéis assumidos por E1 (já assumidos anteriormente), três papéis por E2, dois por E3, fazendo a 
ressalva que existe a tentativa de readquirir o papel de mãe, e um papel por E4. Novamente é possível verificar perdas, desta vez relacionadas com os papéis familiares.

Abordando o papel "Estudantil", anteriormente à situação de sem-abrigo, foram retiradas informações das quatro fontes que nos permitem afirmar que os quatro entrevistados desempenharam o papel de estudante. O insucesso, a abstinência e o abandono escolar precoce é prevalente nas pessoas em situação de sem-abrigo, relacionando-se com carências socioeconómicas, inadaptação ao contexto escolar, ingresso no mercado laboral e desinteresse pela participação na educação ${ }^{23}$. $\mathrm{O}$ abandono escolar foi transversal a três dos indivíduos, por motivos essencialmente relacionados com o trabalho, a falta de interesse escolar ou problemas de saúde: "Foi ai que eu saí a metade do décimo para ir trabalhar. Vi que a escola a mim não me interessava..." (E1). Apenas E4 concluiu a escolaridade mínima obrigatória à data publicada no Diário da República n. ${ }^{\circ} 237 / 1986$ no Decreto-Lei 46/86, não sendo considerado o abandono escolar para este caso, porém foi uma decisão pessoal não prosseguir academicamente ${ }^{24} . \mathrm{Na}$ atual situação de sem-abrigo o papel "Estudantil" apenas se reflete para um caso (E3), o qual está inserido numa turma de formação profissional.

Na subcategoria "Laboral" reconheceu-se que na anterior situação de sem-abrigo os quatro entrevistados se encontravam inseridos laboralmente, E1 como carpinteiro e copeiro, E2 como secretária executiva, E3 como empregada de limpeza e E4 como camionista. Atualmente dois dos entrevistados foram considerados desempregados, E2 e E3 encontram-se reformadas. $\mathrm{O}$ desemprego é uma condição frequente na população em situação de sem-abrigo, sendo esta uma das razões que levam os indivíduos à privação dos bens essenciais?

Estas perdas poderão em parte advir de situações familiares disruptivas, e/ou da dependência de estupefacientes. As primeiras foram comuns a todos os entrevistados, por abandono dos pais biológicos, sendo criados fora deste núcleo por figuras de substituição ou por centros de acolhimento juvenil, ou por conflitos familiares, que conduziram a uma saída precoce da casa dos pais, enquanto que as segundas foram relatadas por duas fontes. Não foi possível situar precisamente no tempo a data em que estas situações emergiram, sabendo apenas que ocorreram antes da situação de sem-abrigo. O culminar de todas estas perdas, caracterizadas pela rutura social do indivíduo com o mercado de trabalho e com a sua estrutura familiar, pode ser definido como o processo de desafiliação que poderá estar intimamente relacionado com o desencadeamento da situação de sem-abrigo ${ }^{25}$.

\section{Objetivos de vida}

Foram encontrados "Objetivos de Vida" comuns às quatro fontes, relacionados com o retorno à atividade laboral. Todos os entrevistados exprimiram interesse noutras áreas. E1 revelou vontade em ingressar novamente no sistema educacional e tem o desejo de ser progenitor, porém ao expor estes dados, demonstrou um discurso não consensual: "Pelo menos é um sonho que eu tenho. Hoje tenho vontade amanhã posso não ter" (E1). Desta forma os investigadores não conseguiram concluir a credibilidade destes objetivos. E2 demonstra querer melhorar a sua situação de saúde e habitacional, como a própria diz: "Melhorar a minha saúde e a minha depressão, ter melhores condições, ou seja, sair daquele apartamento e ir para uma casinha pequenina, um T1, que fosse" (E2). Já E3 pretende estabilizar a sua vida e readquirir o papel de mãe. Por fim, E4 intenta completar a escolaridade mínima obrigatória, restabelecer as ligações interpessoais com alguns dos seus familiares e não consumir estupefacientes.

\section{CONCLUSÃO}

Das categorias e subcategorias estudadas, depreendemse como principais áreas do perfil ocupacional alteradas os "Papéis" e os "Contextos e Ambientes". Existiu de forma transversal uma perda de papéis sociais, ao nível familiar, estudantil e laboral, que poderá estar relacionado com o histórico de dependências, verificado em metade da amostra, e das situações familiares disruptivas comuns aos quatro entrevistados.

O défice de condições básicas habitacionais bem como a perda de papéis, gera a necessidade dos indivíduos em situação de sem-abrigo recorrerem aos apoios sociais como forma de suprir as necessidades básicas. As alterações e a destruturação das rotinas, evidenciada na amostra, refletem-se na privação ocupacional, resultado de um estado prolongado de exclusão no envolvimento de ocupações. Todos os fatores mencionados dão origem a desequilíbrio ocupacional. Assim, conclui-se que o desempenho ocupacional se encontra alterado, não pelas características da pessoa, mas sim pelos contextos e ambientes em que estes indivíduos se inserem, não lhes permitindo aceder/usufruir de um espaço privado e adequado onde possam envolver-se nas suas ocupações.

No contacto estabelecido com os participantes foi notória a dificuldade destes se assumirem como pessoas em situação de sem-abrigo, apesar de demonstrarem desagrado face à sua condição de vida atual. Este facto é indiretamente comprovado pelos objetivos de vida assumidos, revelando desejo em regressar a trabalhar, 
reingressar no ensino escolar, readquirir papéis familiares e estabilizar a vida. Contudo, devido às incoerências encontradas no discurso, os investigadores questionamse sobre a credibilidade da concretização dos interesses enunciados. Pelo menos dois dos entrevistados permanecem na situação de sem-abrigo há mais de dez anos, surgindo a dúvida se não existiram condições ou volição que lhes permitisse concretizar os seus objetivos. A volição está inter-relacionada com o ambiente envolvente, que se encontra alterado na presente população; as condições de acesso a alimentação, higiene, vestuário, saúde e abrigo são garantidas pelos apoios sociais de forma gratuita, não exigindo qualquer retorno. Desta forma, o grupo de investigadores questiona-se sobre os fatores que condicionam a permanência na situação de sem-abrigo, levantando duas questões: Como a volição nas pessoas em situação de sem-abrigo influencia a permanência nesta situação?; As relações que os indivíduos em situação de sem-abrigo estabelecem com os apoios sociais, conduzem à sua permanência nesta situação? Procurando respostas às questões levantadas, o grupo propõe a realização de estudos mais alargados neste âmbito.

Participação dos autores: Todos os autores participaram na conceção e delineação do estudo, na recolha de dados, na análise e interpretação dos mesmos, bem como na redação, revisão crítica da divulgação dos resultados, preservando os princípios formais e éticos tendo todos aprovado a versão a ser publicada.

\section{REFERÊNCIAS}

1. Descritores em Ciências da Saúde (DeCS). São Paulo: BIREME/OPAS/OMS; 2017 [atualizado maio 2017; citado 5 jun. 2019]. Disponível em: http://decs. bvs.br/cgibin/wxis1660.exe/decsserver/

2. Núcleo Executivo do GIMAE. ENIPSSA 2017-2023Sumário Executivo. Portugal: GIMAE; 2018 [citado 5 junho 2019]. Disponível em: http://www.enipssa. pt/ documents/10180/11876/ENIPSSA+2017-2023++Sumário+Executivo/4d02c057-6a26-4fa3-9b43-flb7f77ae3c1

3. GIMAE. Conceito de pessoa em situação de sem-abrigo. [página web] Portugal; GIMAE; 2017 [atualizado 2017; citado 5 junho 2019]. Disponível em: http:// www. enipssa.pt/conceito-de-pessoa-em-situacao-de-semabrigo

4. Homelessness and homeless policies in europe: lessons from Research. European Consensus Conference on Homelessness; 9-19 Dezembro 2010; Bruxelas: FEANTSA; 2010.

5. Quintas SMM. A Percepção de Técnicos e Indivíduos "Sem-Abrigo": Histórias ocultas de uma realidade no Porto. (Dissertação) Mestrado. Porto: Faculdade de Psicologia e de Ciências da Educação- Universidade do Porto; 2010 [citado 31 maio 2019]. Disponível em: https:// repositorio-aberto.up.pt/bitstream/10216/57419/2/29568.pdf

6. Pilar PCP. Perceção de Saúde e Avaliação das Necessidade de Intervenção em População Sem-Abrigo Institucionalizada. (Dissertação) Mestrado. Porto: Universidade Fernando Pessoa;
2015. [citado 31 maio 2019]; Disponível em: https:// bdigital.ufp.pt/bitstream/10284/5368/1/Dissertação Paula Pilar.pdf

7. Instituto da Segurança Social. Quartos, pensões e hospedarias a realidade do alojamento apoiado em Lisboa e no Porto. In: Instituto da Segurança Social. Estudo dos Sem-Abrigo. Lisboa; 2005:173-4. Disponível em: http://www.seg-social. pt/documents/10152/157960/sem_abrigo/e446d027e00a-4d25-a88a-fe18d64c16af

8. Wright J. Health needs of the homeless. InnovAiT. 2013;7(2): 95-8 [citado 31 maio 2019]. https://doi.org/10.1093/ innovaitinr205

9. Christiansen C, Clark F, Kielhofner G, Rogers J. Position paper: occupation. Am J Occup Ther. 1995;49(10):1015-8. https://doi. org/10.5014/ajot.49.10.1015

10. Marques A, Trigueiro MJ. Enquadramento da prática da terapia ocupacional: Domínio \& Processo. $2^{\mathrm{a}}$ ed. Porto: Livpsic; 2011.

11. Kielhofner G. Model of human occupation: theory and application. $4^{\mathrm{a}}$ ed. Philadelphia: Lippincott Williams \& Wilkins; 2008.

12. American Occupational Therapy Association (AOTA). Estrutura da prática da terapia ocupacional: domínio \& processo. $3^{\mathrm{a}}$ ed. trad. Rev Ter Ocup Univ São Paulo. 2015;26:1-49. DOI: https://doi.org/10.11606/issn.2238-6149.v26iespp1-49 
13. Estratégia para a Integração das Pessoas Sem-Abrigo (ENIPSA). Disponível em: https://bityli.com/9ehMY

14. GIMAE. Relatório Inquérito aos Conceitos Utilizados e aos Sistemas Locais de Informação. 2018. [citado 30 maio 2019]. Disponível em: https://bityli.com/Rpueg

15. Yin RK. Pesquisa estudo de caso - desenho e métodos. $2^{\mathrm{a}}$. ed. Porto Alegre: Bookman; 1994 [citado 30 maio 2019]. Disponível em: https://bityli.com/HpV61

16. Souza FN, Costa AP, Moreira A. WebQDA: Software de Apoio à Análise Qualitativa. CISTI; 2010. p.293-8. [citado 29 maio 2019]. Disponível em: https:// bityli.com/WilzT

17. Pardal L, Lopes ES. Métodos e técnicas de investigação social. Porto: Areal Editores; 2011.

18. Sampieri R, Collado C, Lucio P. Metodologia de pesquisa. $5^{\mathrm{a}}$ ed. McGraw Hill; 2015.

19. Bardin L. Análise de conteúdo. $3^{\mathrm{a}}$ ed. Lisboa: Edições 70; 2004.

20. Campos FAL. Caracterização dos estilos de vida dos semabrigo da cidade do Porto [dissertação]. Porto: Escola Superior de Tecnologia da Saúde do Porto, Instituto Politécnico do Porto; 2010 [citado 31 maio 2019]. Disponível em: http://recipp.ipp.pt/handle/10400.22/721
21. Cardoso CAM. O Impacto da ENIPSA nas trajetórias de vida das pessoas sem-abrigo do Porto. [dissertação] Porto: Faculdade de Psicologia e de Ciências da Educação, Universidade do Porto; 2018. [citado 31 maio 2019]. Disponível em: https://repositorio-aberto.up.pt/ handle/10216/112763

22. Barreto ER. Vinculação e relações de objecto dos semabrigo: um estudo exploratório [dissertação]. Lisboa: Instituto de Psicologia Aplicada; 2000 [citado 31 maio 2019]. Disponível em: https://bityli.com/zK6Xx

23. Bastos MVC de L. Percursos escolares de pessoas semabrigo [tese]. Braga: Escola de Psicologia- Universidade do Minho; 2011. [citado 31 maio 2019]. Disponível em: https://bityli.com/yFLm1

24. Portugal. Dec-Lei no 46/86, de 14 de outubro de 1986. Lei de Bases do Sistema Educativo. Diário da República Eletrónico; 1986 out. 14 [citado 4 jun. 2019]. disponível em: https://bityli.com/UgHKt

25. Afonso CMPGM. A Desafiliação do sem-abrigo [dissertação]. Lisboa: Instituto Universitário de Lisboa; 2017 [citado 31 maio 2019]. Disponível em: https://bityli. com $/ 3 \mathrm{mEQc}$ 